\title{
Laparoscopic Cholecystectomy (LC): Toward Zero Error
}

\author{
Danilo Coco ${ }^{1 *}$, Silvana Leanza ${ }^{2}$ \\ Hospital, Jesi (Ancona), Italy
}

${ }^{1}$ Department of General Surgery, Ospedali Riuniti Marche Nord, Pesaro, Italy; ${ }^{2}$ Department of General Surgery, Carlo Urbani

\section{Abstract}

In 1990, laparoscopic cholecystectomy (LC) was considered the new beginning of an exciting period in the management of pathologies associated with gallbladder. Two decades later, biliary morbidity alongside LC is nearly thrice higher compared to conventional open surgery. In the 1990s, Strasberg et al. explained the manner, in which a critical view of safety can be attained and the manner in which vascular injuries and accidental biliary caused by unclear anatomy, incautious control of bleeding, or rare variations could be prevented. The aforementioned principles have been overlooked until recently, only gaining recognition in the past 15 years. This review seeks to explore the aspect of safety in LC based on various techniques.

\section{Introduction}

The important stages in laparoscopic cholecystectomy (LC) feature retraction of gallbladder (GB), dissection within the hepatocystic $(\mathrm{HC})$ triangle for critical view of safety (CVS) attainment, clipping and dividing the cystic artery and cystic duct, and dissecting the GB from the bed.

\section{HC Triangle}

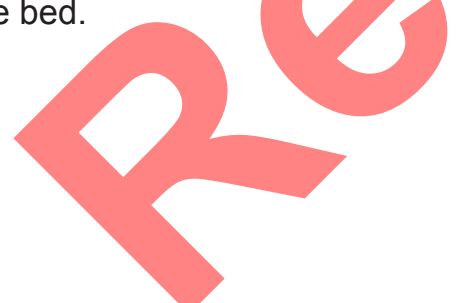

This refers to an area under the liver surface on the right of hepatic hilum. It contains under surface liver cranially, caudal cystic duct, and medially located common hepatic duct (CHD) (Figure 1) [1], [2]. The triangle features variable quantities of fibrofatty connective tissues, lymphatic, cystic lymph nodes, variable portions of right hepatic artery, and cystic artery [1].

Essentially, the $\mathrm{HC}$ triangle constitutes the area of target for dissection in LC. The triangle differs from the Calot's triangle where cystic artery forms cephalad boundary rather the surface of the liver [1], [2].

The CVS technique refers to target identification means, the targets include artery and cystic duct. It was unveiled. CVS depends on anatomic identification

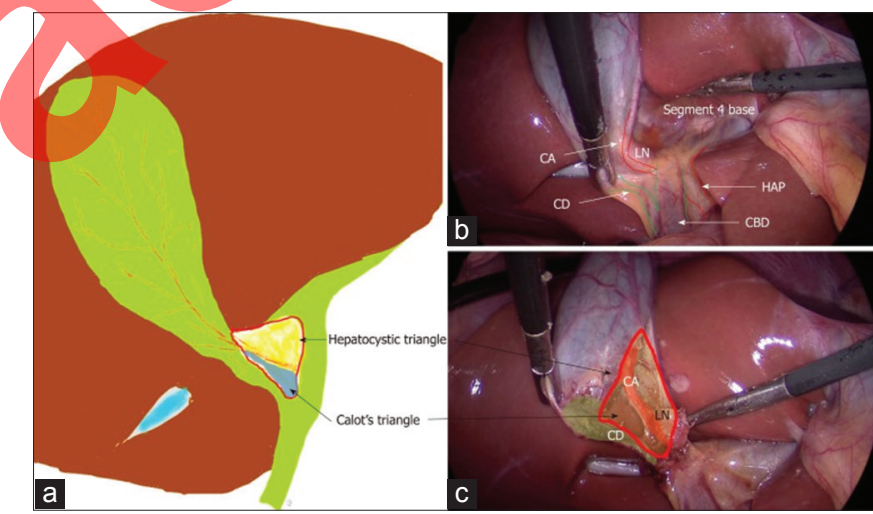

Figure 1: Anatomy of hepatocystic $(H C)$ and Calot's triangles. a: $H C$ triangle (red outline); Calot's triangle (in blue); relevant anatomical structures; b: Before dissection; c: After dissection. CD: Cystic duct; CA: Cystic artery; LN: Lymph node; HAP: Hepatic artery proper; $C B D$ : Common bile duct

method within open CS. The three CVS elements include clearance of fibrous tissue and fat from $\mathrm{HC}$ triangle, taking lower GB parts off the cystic plate, and seeing only two structures that are joining the GB.

\section{Rouviere's Sulcus}

The length of this sulcus is $2-5 \mathrm{~cm}$ and it exists on the liver's right lobe under surface, extending to 


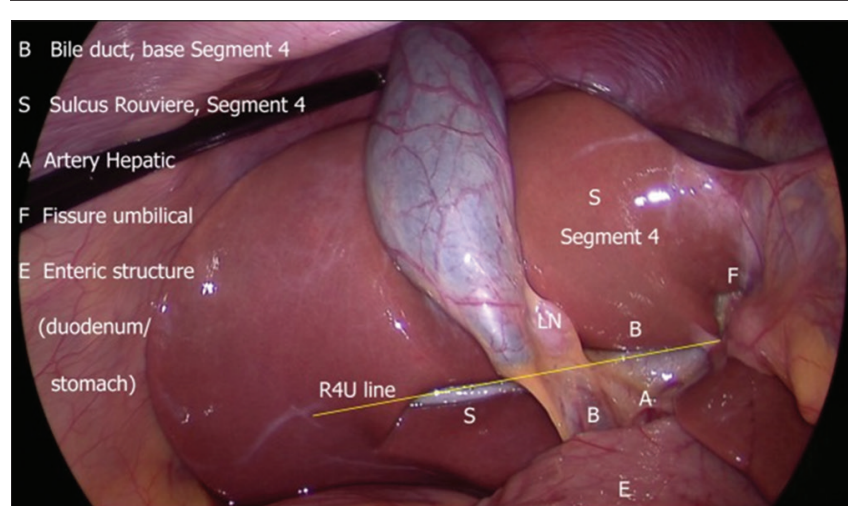

Figure 2: R4U safety line and B-SAFE anatomical landmarks. When Rouviere's sulcus does not exist, then the line cutting across the segment 4 base from the fissure of the umbilical might extend to the right across hepatoduodenal ligaments confirming safe dissection zone (Figure 3)

hepatic hilum [3], [4], [5], [6], as illustrated in Figure 2. It can be seen in about $80 \%$ of cases, wherein it remains fully or partially open and mainly features right portal pedicle and its branches [3], [4], [5], [6]. During LC, one can see it when the neck of the GB retracts to the fissure of the umbilical cord, as illustrated in Figure 3.

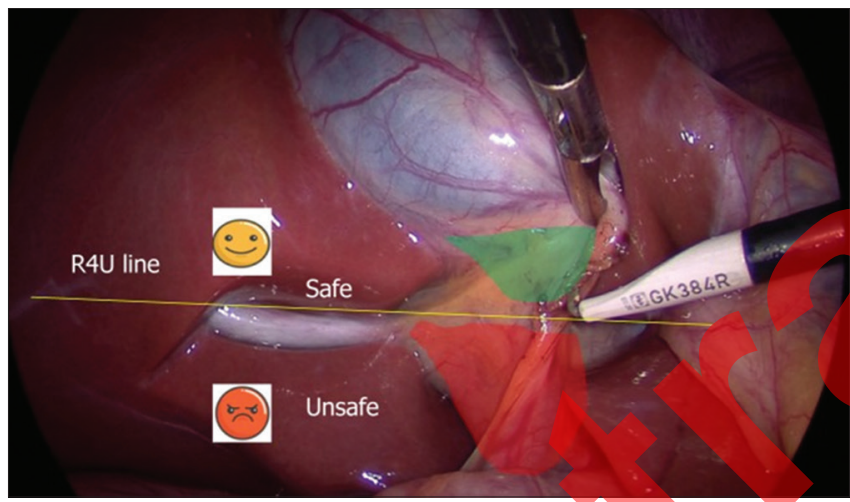

Figure 3: Surgical fields of interest in laparoscopic cholecystectomy. It is imperative to locate red (danger) and green (safe) dissection zones based on R4U line demarcation

\section{Correct Display/Exposure of the HC Triangle Before Dissection}

In LC, the main surgical field of interest is the $\mathrm{HC}$ triangle. It is imperative that this area is exposed before commencing the actual dissection. This necessitates the GB to be retracted properly. Extraction of the fundus must be undertaken to the patient's right shoulder, whereas extraction of the infundibulum must be undertaken inferolaterally to the patient's right side, as illustrated in Figure 4 [7].

When retraction of the neck (infundibulum) is done toward the umbilical fissure, it is possible to see the $\mathrm{HC}$ triangle posterior aspect (Figure 5). In the event of inadequate retraction of the infundibulum in the required direction, the common bile duct (CBD)

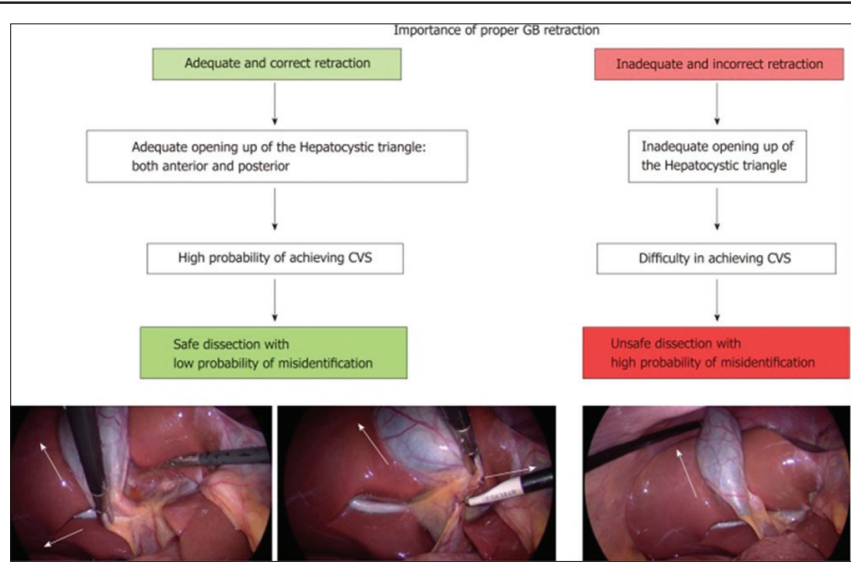

Figure 4: Importance of proper retraction of gallbladder during laparoscopic cholecystectomy

would be pulled to the patient's right upper quadrant, leading to parallel alignment for the CBD and cystic duct (Figure 5).

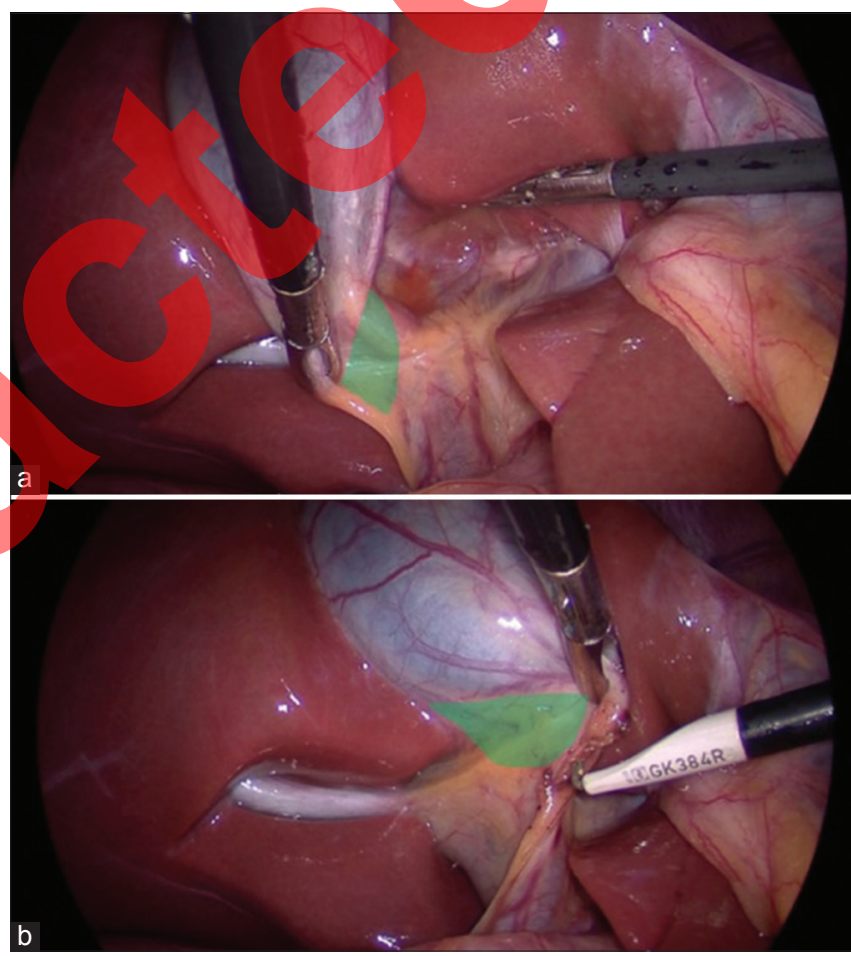

Figure 5: Proper retraction of infundibulum (neck) allows. (a) Exposure of anterior aspect of hepatocystic $(\mathrm{HC})$ triangle when retraction of infundibulum is done in the right inferolateral direction; (b) exposure of HC triangle's posterior aspect when retraction of infundibulum is done toward the umbilical fissure

\section{Judicious Use of Energy Sources}

Energy devices utilized for dissecting the $\mathrm{HC}$ triangle as well as for separating the GB the bed are ultrasound, bipolar cautery, and monopolar cautery energy devices. Although monopolar cautery is utilized widely, existing evidence is insufficient to propose one 
at the expense of others on the basis of safety [8]; with ultrasound device, the operative duration might be shorter [9], [10], [11]. All the aforementioned sources of energy are considered ideal in achieving safe cholecystectomy. There is a need for the operating surgeon to understand how such energy devices should be handled safely.

\section{Concept of the CVS}

Structure misidentification within the $\mathrm{HC}$ triangle commonly causes biliary injury in LC. Division

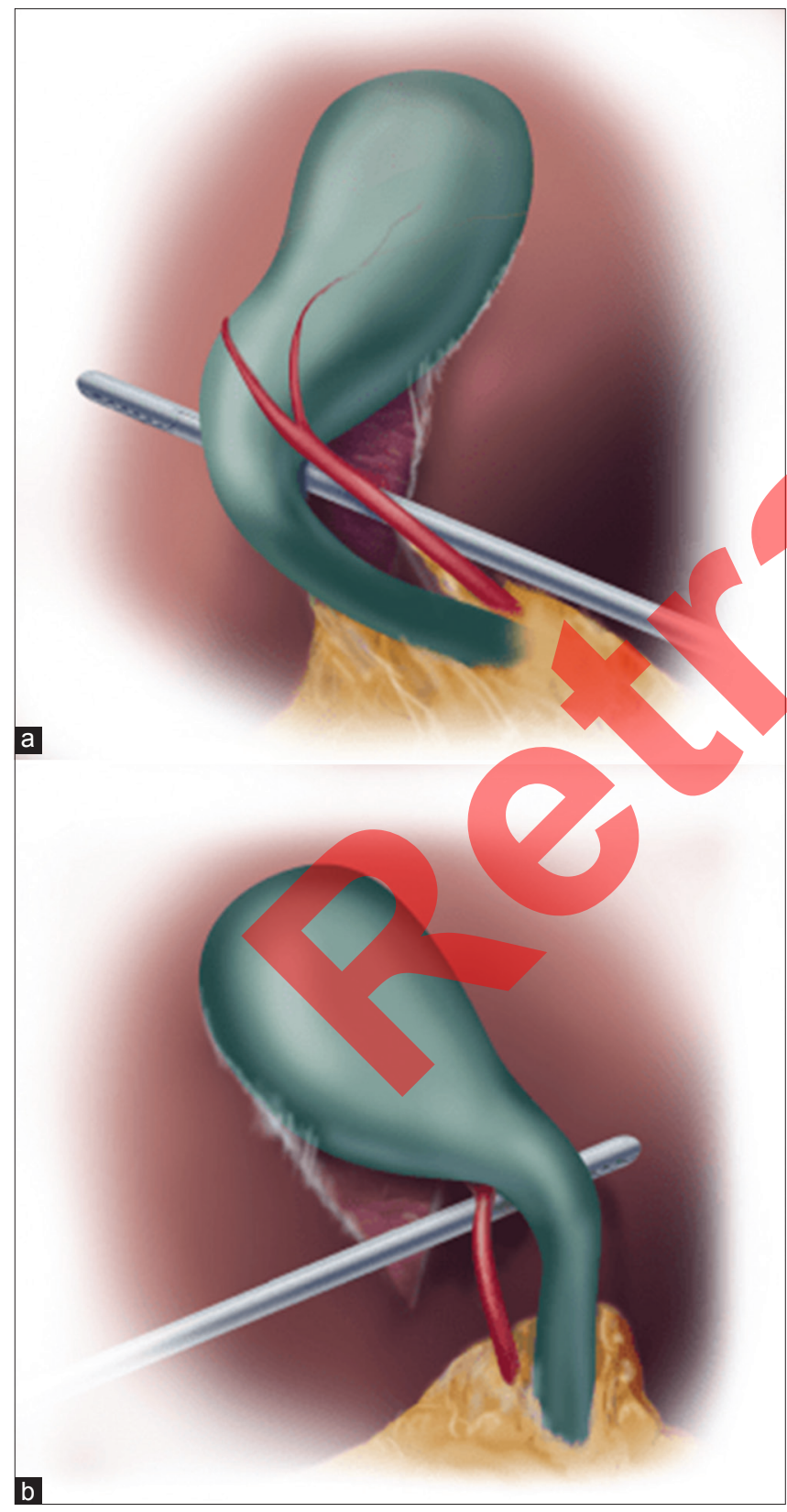

Figure 6: (a) Critical view of safety anterior view. (b) Critical view of safety posterior view and clipping of aberrant right sectional ducts or the CBD for misidentification as cystic ducts might occur [11]. Similarly, misidentification of the right hepatic artery as the cystic artery might occur when an aberrant course exists for the right hepatic artery or when the cystic artery is short. To overcome such injury of misidentification, it is imperative that conclusive identification of both structures (cystic duct and cystic artery) is undertaken before clipping and division. Introduction of CVS concept sought to reduce injuries associated with misidentification [12]. CVS seeks to conclusively identify the cystic artery and the cystic duct to avert misidentification injuries [13], [14], [15]. Figure $6 a$ and $b$ shows the CVS anterior and posterior views.

A doublet view can be used for CVS confirmation [16]. The doublet view has two components, which are doublet view visualization (anterior) and doublet view visualization (posterior), as illustrated in Figure $7 a$ and $b$.
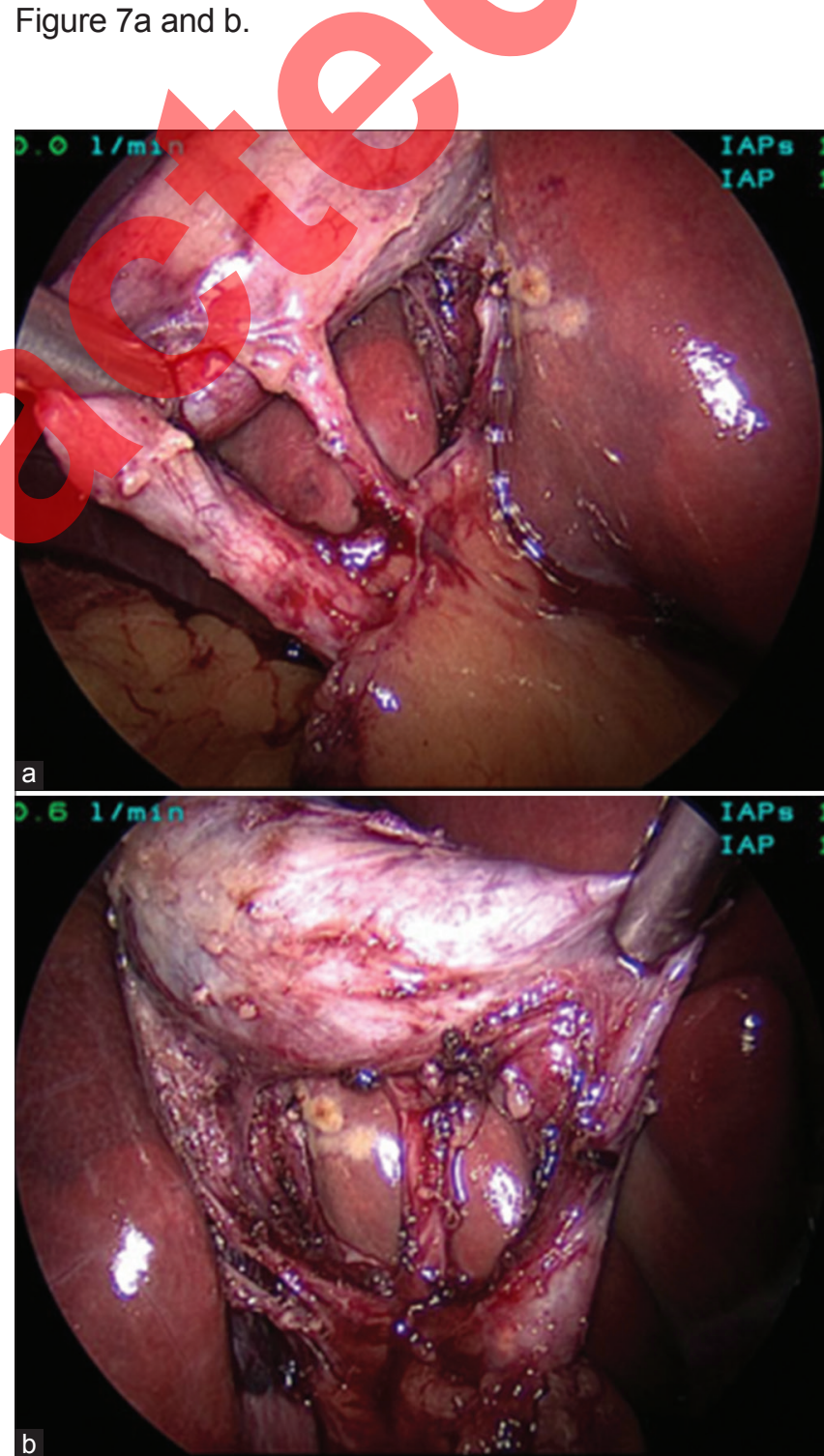

Figure 7: (a) Visualization of the doublet view (anterior) (b) Visualization of the doublet view (posterior) 


\section{Intraoperative Cholangiography (IOC)}

IOC is a widely studied and commonly performed method used for biliary anatomy intraoperative assessment, assessment and identification of biliary injury extent, and potential prevention of biliary ductal injuries. Many large sets of retrospective data have found a correlation between lower Baltic Dry Index (BDI) rates and IOC [17]. Extensive research has shown that IOC might reduce $B D I$ possibilities and earlier identification of injuries. Nevertheless, the numerous pitfalls that characterize it might prevent its application in routine clinical practices. It is still debatable regarding whether performance of IOC should be selective or routine; on the basis of existing literature, recommending routine IOC is not feasible [7].

\section{Target identification Techniques}

Numerous target identification techniques during LC exist. Besides CVS, other techniques have been relied on by surgeons in locating anatomy in LC; they include intraoperative cholangiogram, fundus first technique, and infundibular techniques [17]. Nevertheless, such techniques, particularly the fundus first and infundibular, might be misleading in some instances and might serve as error traps to unsuspecting surgeons [18].

\section{Infundibular Technique}

Regarding the infundibular technique, identification of cystic duct depends on the funnellike appearance of infundibulum-cystic duct junction [13], [14], [18]. In the event circumferential exposure of the junction, the surgeon confirms the identification of cystic duct and then proceeds with the division. Total dissection within the $\mathrm{HC}$ triangle is not conducted in this phase. In some instances, the technique could be misleading. When the cystic duct undergoes fusing with CHD because of chronic or acute inflammation, when large stones impacted within the infundibulum efface the cystic duct, or when challenges exist in the exposure of $\mathrm{HC}$ triangle because of inadequate retraction (for instance, because of fibrosis), misidentification of CBD as cystic duct could occur [18]. Instead of circumferential dissection going around the cystic ducts across the $\mathrm{HC}$ triangle, it goes around the $\mathrm{CBD} / \mathrm{CHD}$. This results in classical BDI where division of the bile duct occurs twice before complete separation of the liver and the GB. Therefore, the cystic duct identification technique does not offer protection against biliary injury under complex circumstances. This error trap should be known to surgeons applying the technique.

\section{Fundus First Technique (Dome-down Technique)}

Regarding the fundus-first technique, dissection of the GB from the cystic plate/bed plate is undertaken followed by identification and division of the artery and cystic duct [19], [20], [21]. Widely used in open cholecystectomy, the technique presents technical challenges in dealing with the GB because it appears to twist after complete separation from the liver. Moreover, liver retraction is complex.

\section{Laparoscopic Ultrasound (LUS)}

Extensive outcome research complements LUS for BDI prevention [22]. It is considered safe because of its non-invasiveness. Some benefits linked to IOC include absence of exposure to radiation, higher rates of success, shorter period of procedure, and non-invasiveness. Nevertheless, it is inaccurate in intrahepatic and intrapancreatic biliary system's parts. Moreover, its learning curve is long. At present, LUS constitutes an ideal option to IOC for CBD stone diagnosis [23]. Figure 8 shows laparoscopic ultrasonographic.

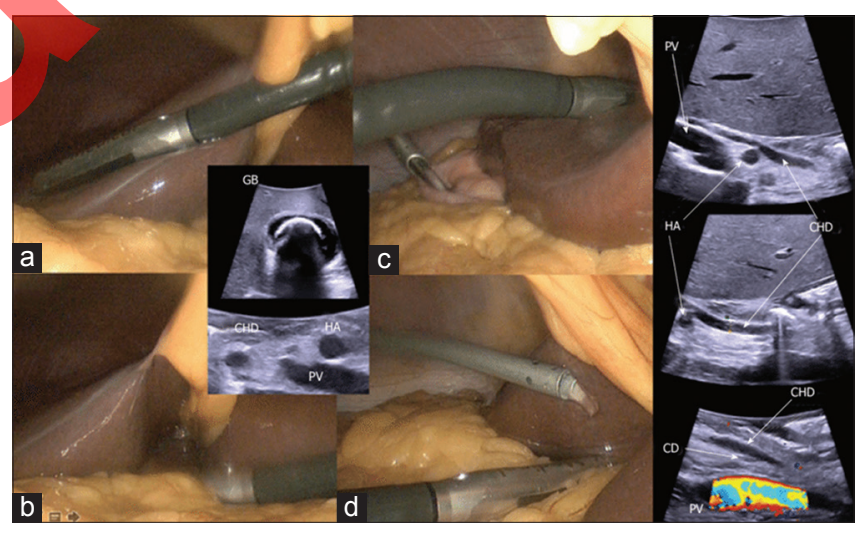

Figure 8: Laparoscopic ultrasonography technique. Transversal approach - a: Through the liver; $b$ : Directly on the hepatoduodenal pedicle. Longitudinal approach - c: Through the liver; d: Directly on the hepatoduodenal pedicle (isotonic solution's irrigation that improves acoustic coupling). Cd: Cystic duct junction with the common bile duct; $\mathrm{CHd:} \mathrm{Common} \mathrm{hepatic} \mathrm{duct;} \mathrm{HA:} \mathrm{Hepatic} \mathrm{artery;}$ PV: Portal vein; GB: Gallbladder with macrolithiasis

\section{Near-infrared Fluorescent Cholangiography}

This technique is the latest addition to armamentarium for intraoperative biliary tract assessment. Numerous studies have confirmed its safety and efficacy [24]. When compared against IOC, the technique is safer, cheaper and takes less time. 
Nevertheless, because it is an emerging technique, using it in different biliary pathologies is yet to be evaluated. At present, there is insufficient evidence for recommending its routine application in the detection of BDI or CBD stones [8]. Figure 9 shows intraoperative assessment of biliary anatomy with NIRFC after partial dissection of Calot's triangle using the Novadaq ${ }^{\mathrm{TM}}$ Pinpoint Endoscopic Fluorescence Imaging System.

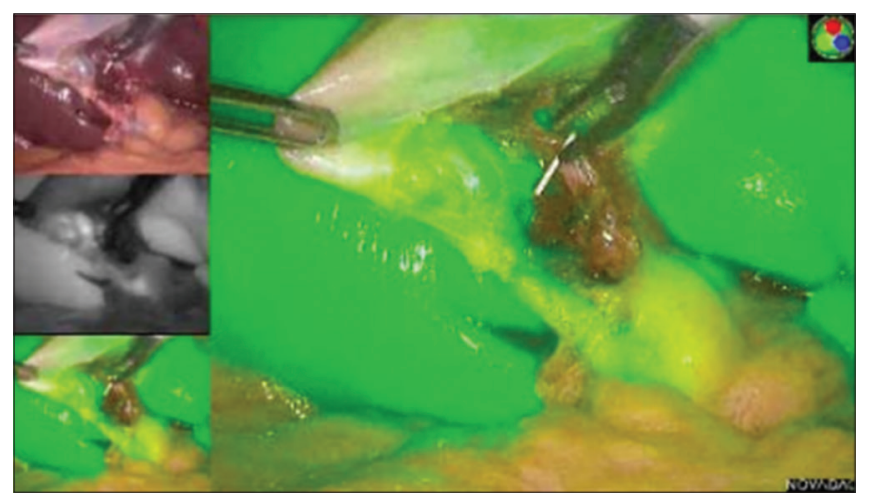

Figure 9: Intraoperative assessment of biliary anatomy with NIRFC after partial dissection of Calot's triangle using the Novadaq ${ }^{\mathrm{TM}}$ Pinpoint Endoscopic Fluorescence Imaging System

\section{Triangle of Safety Technique (TST)}

TST seeks to provide another safe dissection triangle. In TST, identification and mobilization of cystic artery from the GB medial wall is done downward to the cystic duct, which would concurrently divide the medial GB peritoneal attachment. Afterward, this is followed by separating the attachment of the lateral peritoneal. TST borders are achieved (the GB wall superiorly, cystic duct laterally, and cystic artery medially) when unfolding of the GB is done.

In TST, dissection begins in a region away from the Calot's triangle where arterial or ductal anomalies are non-existent. After review of artery and cystic duct anomalies within the literature, it was found that majority exist at Calot's triangle level [13], [16], [25], [26], [27], [28]. This area is spared by TST. Indeed, the cystic artery proper alongside the terminal branches is constant and creates reliable landmarks for initiating dissection. In addition, tracking the branches of cystic artery from the walls of the GB would explain whether a posterior branch that could be preserved for dissection after TST view is identified, exists. Figure 10 shows how tissues are divided in TST.

Seemingly, TST is a safe technique that clearly shows the cystic duct's anatomy and decreases issues of misidentification as well as the necessity for IOC. Because TST dissection takes place some distance from Calot's triangle, the likelihood for arterial or ductal anomalies does not exist and this decreases post- and intraoperative complications.

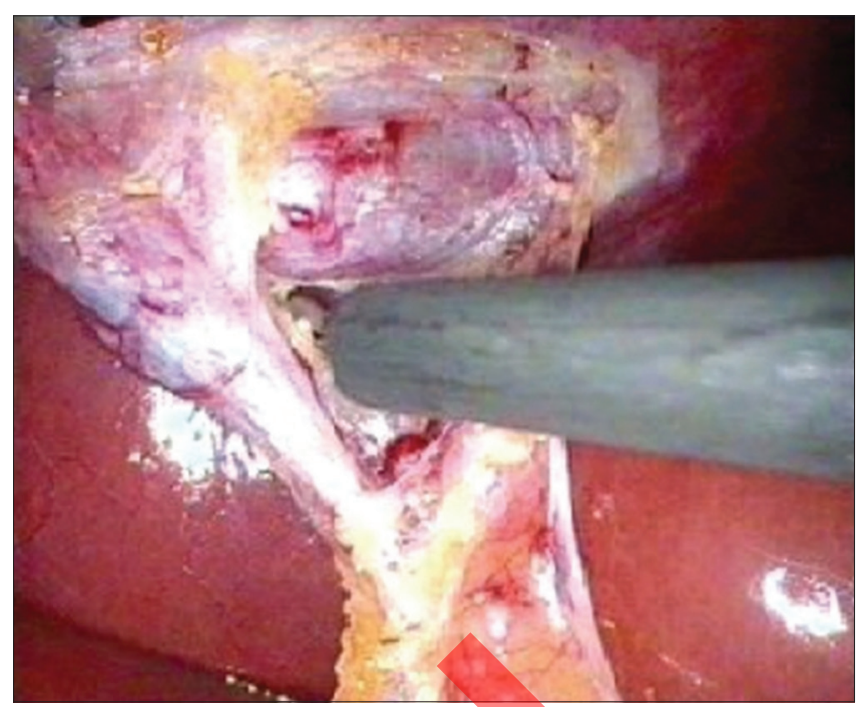

Figure 10: Division of tissues in triangle of safety technique

\section{Conclusion}

This review explored the aspect of safety in LC based on various techniques. Overall, it could be inferred that biliary injuries following LC could lead to significant morbidity. The surgical team taking part in LC must understand the "culture of safety in cholecystectomy" (COSIC) concept [29]. The entire team must routinely adopt this universal safety culture in each case [30]

\section{References}

1. Abdalla $S$, Pierre $S$, Ellis $H$. Calot's triangle. Clin Anat 2013;26(4):493-501. https://doi.org/10.1002/ca.22170 PMid:23519829

2. Skandalakis JE, Skandalakis PN, Skandalakis LJ. Surgical Anatomy and Technique. $2^{\text {nd }}$ ed. Berlin: Springer-Verlag; 2000. p. 573-612. https://doi.org/10.1007/978-1-4615-7993-9_14

3. Hugh TB, Kelly MD, Mekisic A. Rouvière's sulcus: A useful landmark in laparoscopic cholecystectomy. $\mathrm{Br} \mathrm{J}$ Surg. 1997;84(9):1253-4. https://doi.org/10.1002/bjs.1800840916 PMid:9313706

4. Dahmane R, Morjane A, Starc A. Anatomy and surgical relevance of Rouviere's sulcus. ScientificWorldJournal. 2013;2013:254287. https://doi.org/10.1155/2013/254287

5. Lockhart S, Singh-Ranger G. Rouviere's sulcus-Aspects of incorporating this valuable sign for laparoscopic cholecystectomy. Asian J Surg. 2018;41(1):1-3. https://doi. org/10.1016/j.asjsur.2016.07.012

PMid:27647607

6. Peti N, Moser MA. Graphic reminder of Rouviere's sulcus: Auseful landmark in cholecystectomy. ANZ J Surg. 2012;82(5):367-8. https://doi.org/10.1111/j.1445-2197.2012.06032.x PMid:23305052

7. Eikermann M, Siegel R, Broeders I, Dziri C, Fingerhut A, Gutt C, et al. Prevention and treatment of bile duct injuries during laparoscopic cholecystectomy: The clinical practice guidelines of the European association for endoscopic surgery (EAES). 
Surg Endosc. 2012;26:3003-39. https://doi.org/10.1007/ s00464-012-2511-1

8. Conrad C, Wakabayashi G, Asbun HJ, Dallemagne B, Demartines N, Diana M, et al. IRCAD recommendation on safe laparoscopic cholecystectomy. J Hepatobiliary Pancreat Sci. 2017;24(11):603-15. https://doi.org/10.1002/jhbp.491 PMid:29076265

9. Kandil T, El Nakeeb A, El Hefnawy E. Comparative study between clipless laparoscopic cholecystectomy by harmonic scalpel versus conventional method: A prospective randomized study. J Gastrointest Surg. 2010;14:323-8. https://doi. org/10.1007/s11605-009-1039-8

PMid:19882194

10. El Nakeeb A, Askar W, El Lithy R, Farid M. Clipless laparoscopic cholecystectomy using the Harmonic scalpel for cirrhotic patients: A prospective randomized study. Surg Endosc. 2010;24(10):2536-41. https://doi.org/10.1007/ s00464-010-0999-9

PMid:20376490

11. Jain SK, Tanwar R, Kaza RC, Agarwal PN. A prospective, randomized study of comparison of clipless cholecystectomy with conventional laparoscopic cholecystectomy. J Laparoendosc Adv Surg Tech A. 2011;21(3):203-8. https://doi.org/10.1089/ lap.2010.0455

PMid:21375416

12. Strasberg SM. Avoidance of biliary injury during laparoscopic cholecystectomy. J Hepatobiliary Pancreat Surg. 2002;9(5):543-7. https://doi.org/10.1007/s005340200071

PMid: 12541037

13. Strasberg SM, Hertl M, Soper NJ. An analysis of the problem of biliary injury during laparoscopic cholecystectomy. J Am Coll Surg. 1995;180(1):101-25.

PMid:8000648

14. Strasberg SM, Brunt LM. Rationale and use of the critical view of safety in laparoscopic cholecystectomy. $\mathrm{Am}$ Coll Surg. 2010;211(1):132-8. https://doi.org/10.1016/j. jamcollsurg.2010.02.053 PMid:20610259

15. Strasberg SM. Biliary injury in taparoscopic surgery: Part 2. Changing the culture of cholecystectomy. $\mathrm{J}$ Am Coll Surg. 2005;201(4):604-11. https://doi.org/10.1016/j. jamcollsurg.2005.04.032 PMid: 16183501

16. Goor DA, Ebert PA. Anomalies of the biliary tree. Report of a repair of an accessory bile duct and review of the literature. Arch Surg. 1972;104(3):302-9. https://doi.org/10.1001/ archsurg.1972.04180030050012 PMid:5010841

17. Strasberg SM. A perspective on the critical view of safety in laparoscopic cholecystectomy. Ann Laparosc Endosc Surg. 2017;2:91. https://doi.org/10.21037/ales.2017.04.08

18. Strasberg SM, Brunt LM. The critical view of safety: Why it is not the only method of ductal identification within the standard of care in laparoscopic cholecystectomy. Ann Surg. 2017;265(3):464-5. https://doi.org/10.1097/sla.0000000000002054

\section{PMid:27763898}

19. Strasberg SM. Error traps and vasculo-biliary injury in laparoscopic and open cholecystectomy. J Hepatobiliary
Pancreat Surg. 2008;15(3):284-92. https://doi.org/10.1007/ s00534-007-1267-9

PMid:18535766

20. Mahmud S, Masaud M, Canna K, Nassar AH. Fundus-first laparoscopic cholecystectomy. Surg Endosc. 2002;16(4):581-4. https://doi.org/10.1007/s00464-001-9094-6

PMid:11972192

21. Gupta A, Agarwal PN, Kant R, Malik V. Evaluation of fundus-first laparoscopic cholecystectomy. JSLS. 2004;8(3):255-8.

PMid:15347114

22. Tuveri M, Calò PG, Medas F, Tuveri A, Nicolosi A. Limits and advantages of fundus-first laparoscopic cholecystectomy: Lessons learned. J Laparoendosc Adv Surg Tech A. 2008;18(1):69-75. https://doi.org/10.1089/lap.2006.0194 PMid: 18266578

23. Machi J, Johnson JO, Deziel DJ, Soper NJ, Berber E, Siperstein A, et al. The routine use of laparoscopic ultrasound decreases bile duct injury: A multicenter study. Surg Endosc. 2009;23(2):384-8. https://doi.org/10.1007/s00464-008-9985-x PMid: 18528611

24. Buddingh KT, Nieuwenhuijs VB, van Buuren L, Hulscher JB, de Jong JS, van Dam GM. Intraoperative assessment of biliary anatomy for prevention of bile duct injury: A review of current and future patient safety interventions. Surg Endosc. 2011;25(8):2449-61. https://doi.org/10.1007/ s00464-011-1639-8 PMid:21487883

25. Alvarez $F A$, de Santibañes M, Palavecino M, Clariá RS Mazza O, Arbues G, et al. Impact of routine intraoperative cholangiography during laparoscopic cholecystectomy on bile duct injury. $\mathrm{Br}$ J Surg. 2014;101(6):677-84. https://doi. org/10.1002/bjs.9486

\section{PMid:24664658}

Osayi SN, Wendling MR, Drosdeck JM, Chaudhry UI, Perry KA Noria SF, et al. Near-infrared fluorescent cholangiography facilitates identification of biliary anatomy during laparoscopic cholecystectomy. Surg Endosc. 2015;29(2):368-75. https://doi. org/10.1007/s00464-014-3677-5

PMid:24986018

27. Balija M, Huis $M$, Nikolić $V$, Štulhofer M. Laparoscopic visualization of the cystic artery anatomy. World J Surg. 1999;23(7):703-7. https://doi.org/10.1007/pl00012372 PMid: 10390590

28. Puente SG, Bannura GC. Radiological anatomy of the biliary tract: Variations and congenital abnormalities. World J Surg. 1983;7(2):271-6. https://doi.org/10.1007/bf01656159 PMid:6868640

29. Strasberg SM. A teaching program for the "culture of safety in cholecystectomy" and avoidance of bile duct injury. J Am Coll Surg. 2013;217(4):751. https://doi.org/10.1016/j. jamcollsurg.2013.05.001 PMid:23707046

30. Sanford DE, Strasberg SM. A simple effective method for generation of a permanent record of the critical view of safety during laparoscopic cholecystectomy by intraoperative "doublet" photography. J Am Coll Surg. 2014;218(2):170-8. https://doi. org/10.1016/j.jamcollsurg.2013.11.003

PMid:24440064 